\title{
Comparison of nifedipine and diltiazem with salbutamol for prevention of preterm delivery in the ovariectomized, oestrogen-treated late pregnant rat
}

\author{
M. H. Abel* and M. Hollingsworth \\ Department of Pharmacology, Materia Medica \& Therapeutics, Stopford Building, \\ University of Manchester, Oxford Road, Manchester M13 9PT, U.K.
}

\begin{abstract}
Summary. The ovariectomized, oestrogen-treated, late pregnant rat has been used to compare the ability of two calcium antagonists, diltiazem and nifedipine, with an agonist at $\beta$-adrenoceptors, salbutamol, to prevent the development of uterine contractions, prolong gestation and maintain fetal survival in utero. Preterm delivery of the fetuses was not prevented in the animals infused with salbutamol $(2 \mu \mathrm{g} / \mathrm{kg} / \mathrm{min})$, occurring at the same time, $30-40 \mathrm{~h}$ after ovariectomy, as in the saline-infused rats. The overall integral of uterine contractions was significantly reduced in the salbutamoltreated compared with the saline-treated animals due to decreased contractions after abortion. Both diltiazem $(100 \mu \mathrm{g} / \mathrm{kg} / \mathrm{min})$ and nifedipine $(3 \cdot 1$ and $6.2 \mu \mathrm{g} / \mathrm{kg} / \mathrm{min})$ produced significant inhibition of uterine contractions and in contrast to salbutamol prolonged gestation and improved fetal survival in utero as assessed at post mortem on Day 21 . However, maternal survival was low $(57 \%)$ with the higher dose of nifedipine, possibly reflecting the relaxant effect of this compound on vascular smooth muscle with consequent underperfusion of vital organs.
\end{abstract}

\section{Introduction}

The aetiology of preterm labour is multifactorial and often of unknown cause and therefore therapy has been aimed at inhibition of uterine contractions. Agonists at $\beta$-adrenoceptors, such as ritodrine and salbutamol, are the current first line drugs to treat preterm labour (Lippert, 1983), presumably due to interaction with uterine $\beta$-adrenoceptors causing suppression of uterine contractions. However, these compounds have had only limited success in preventing preterm labour. This is due in part because the dose which can be given is restricted by side effects such as tachycardia and tremor (Lippert, 1983). In addition, there is evidence of the development of significant tolerance (= reduction in sensitivity) to the inhibition of uterine contractions produced by $\beta$-adrenoceptor agonists after their administration in vivo (Johansson \& Andersson, 1981; Rydén, Andersson \& Berg, 1982; Abel \& Hollingsworth, 1985b, 1986; Berg, Andersson \& Rydén, 1985).

Tension development by uterine smooth muscle is predominantly dependent on extracellular calcium ions $\left(\mathrm{Ca}^{2+}\right)$ which can enter the cytoplasm via voltage-dependent channels in the cell membrane (Edman \& Schild, 1962; Bolton, 1979). A group of structurally diverse compounds, known as calcium antagonists, will inhibit $\mathrm{Ca}^{2+}$ entry into cells via these channels. Several of these calcium antagonists have been shown to be potent inhibitors of tension development by uterine smooth muscle in vitro by inhibition of $\mathrm{Ca}^{2+}$ influx (Granger, Hollingsworth \& Weston, 1985, 1986). Calcium antagonists have also been shown to inhibit uterine contractions acutely in vivo in both the rat (Csapo, Puri, Tarro \& Henzl, 1982; Abel \& Hollingsworth, 1985a) and the human (Forman, Andersson \& Ulmsten, 1981). Two of the compounds, nifedipine and diltiazem, showed some selectivity for inhibition of uterine contractions relative to their effects on the cardiovascular

*Present address: Department of Biological Sciences, University of Warwick, Coventry CV4 7AL, U.K. 
system after bolus i.v. administration (Abel \& Hollingsworth, 1985a). This action on the uterus is probably responsible for the ability of calcium antagonists to prolong normal delivery in the rat when administered acutely at term (Csapo et al., 1982; Hahn, McGuire, Vanderhoof, Ericson \& Pasquale, 1984). There has been relatively little study of the effects of members of either pharmacological group on the length of gestation when administered over longer periods. Nitrendipine, a calcium antagonist, given to rats on Days 20 and 21 or Days 18-21 of pregnancy increased the duration of parturition (Sakamoto \& Hucszar, 1984). Nicardipine, another calcium antagonist, delayed the onset of preterm delivery when given over several days to ovariectomized, oestrogentreated late pregnant rats (Csapo et al., 1982). We are not aware of any studies of the ability of agonists at $\beta$-adrenoceptors to delay preterm labour in animals. The present study was therefore undertaken to compare the ability of nifedipine and diltiazem with that of salbutamol to suppress uterine contractions, prolong gestation and maintain fetal survival in utero, in a rat model of preterm labour: the ovariectomized, oestrogen-treated late pregnant rat.

\section{Materials and Methods}

Animals. Pregnant Sprague Dawley rats, 250-350 g, were supplied by the Animal Unit, Manchester University. Day of mating was designated Day 1. Bilateral ovariectomy, jugular vein cannulation, uterine balloon placement and connection of the balloon cannula via a swivel to a pressure transducer were performed between 10:00 and 14:00 h on Day 18 of gestation by techniques similar to those described by Abel \& Hollingsworth (1985a). The uterine balloon was usually placed between the two fetuses nearest to the right ovary. At operation, before ovariectomy, $0.6 \mathrm{ml}$ blood was collected from the jugular vein for later measurement of plasma progesterone concentrations. Oestradiol benzoate (Sigma, Poole, Dorset, U.K.), $0.5 \mu \mathrm{g} / \mathrm{kg}$ in arachis oil (Sigma), was given subcutaneously every $12 \mathrm{~h}$, commencing at operation.

Assessment of drug effects. Animals were allowed $5 \mathrm{~h}$ to recover from surgery and then drugs were infused intravenously, in a volume not exceeding $0.4 \mathrm{ml} / \mathrm{h}$, for $67 \mathrm{~h}$. Initially the drugs were infused at approximately equi-effective dose rates, those which just abolished uterine contractions in the ovariectomized, post-partum rat (Abel \& Hollingsworth, 1985b, 1986). These dose rates were $2 \mu \mathrm{g}$ salbutamol $/ \mathrm{kg} / \mathrm{min}, 25 \mu \mathrm{g}$ nifedipine $/ \mathrm{kg} / \mathrm{min}$ but reduced to $3 \cdot 1$ or $6 \cdot 2 \mu \mathrm{g} / \mathrm{kg} / \mathrm{min}$ (see 'Results') and $200 \mu \mathrm{g}$ diltiazem $/ \mathrm{kg} / \mathrm{min}$, reduced to $100 \mu \mathrm{g} / \mathrm{kg} / \mathrm{min}$ (see 'Results'). Intrauterine pressure was recorded continuously from 25 to $72 \mathrm{~h}$ after ovariectomy on a 2-channel polygraph (Grass Instruments, Quincy, MA, U.S.A) and quantified as the integral of intrauterine pressure above basal pressure using a 7P10B integrator pre-amplifier. A rise in intrauterine pressure was assumed to be due to a contraction of the uterus. On Day $21,72 \mathrm{~h}$ after surgery, a second blood sample was collected by cardiac puncture under ether anaesthesia. The animals were then killed and the uterus removed and weighed. Individual fetuses and placentae were counted and weighed. The number of fetuses in utero was expressed as a percentage of those present on Day 18. Fetal and placental weights were compared with those of unoperated animals killed on Days 18, 19, 20 and 21 of gestation.

Progesterone assay. Progesterone concentrations in plasma were determined by Dr M. Dukes, ICI plc (Pharmaceuticals Division), using a radioimmunoassay described by Williams, Hollingsworth, Dukes \& Morris (1983). Progesterone, $\left[{ }^{3} \mathrm{H}\right]$ progesterone and highly purified antiserum were obtained from Sigma, Amersham International Ltd (Amersham, Bucks, U.K.) and Steranti Research (St Albans, Herts, U.K.) respectively. The intra-assay and inter-assay coefficients of variation were $6 \cdot 2 \%$ and $15 \cdot 1 \%$ respectively and the sensitivity of the assay was $50 \mathrm{pg} / \mathrm{ml}$.

Drugs and statistics. The following drugs were used; nifedipine (Bayer, Newbury, Berks, U.K.) (+)-cis diltiazem $\mathrm{HCl}$ (Synthelabo, Paris, France) and salbutamol sulphate (Glaxo, Ware, Herts, 
U.K.). Solutions of diltiazem and salbutamol were prepared in sterile saline (Travenol Lab. Ltd, Thetford, Norfolk, U.K.). Nifedipine solutions were prepared in polyethylene glycol 400:ethanol: saline (15:15:50; by vol.). Fresh solutions of nifedipine were prepared every $12 \mathrm{~h}$, protected from direct light and experiments were carried out under sodium light. Doses are expressed in terms of the weight of base and not the salt of the drug. Values are given as means \pm s.e.m. The significance of differences between groups was ascertained by a two-tailed Student's $t$ test.

\section{Results}

\section{Saline-infused animals}

In 6 animals which received a continuous infusion of saline, regular bursts of uterine contractions were observed which increased in amplitude throughout the $48 \mathrm{~h}$ of recording (Fig. 1). Two peaks

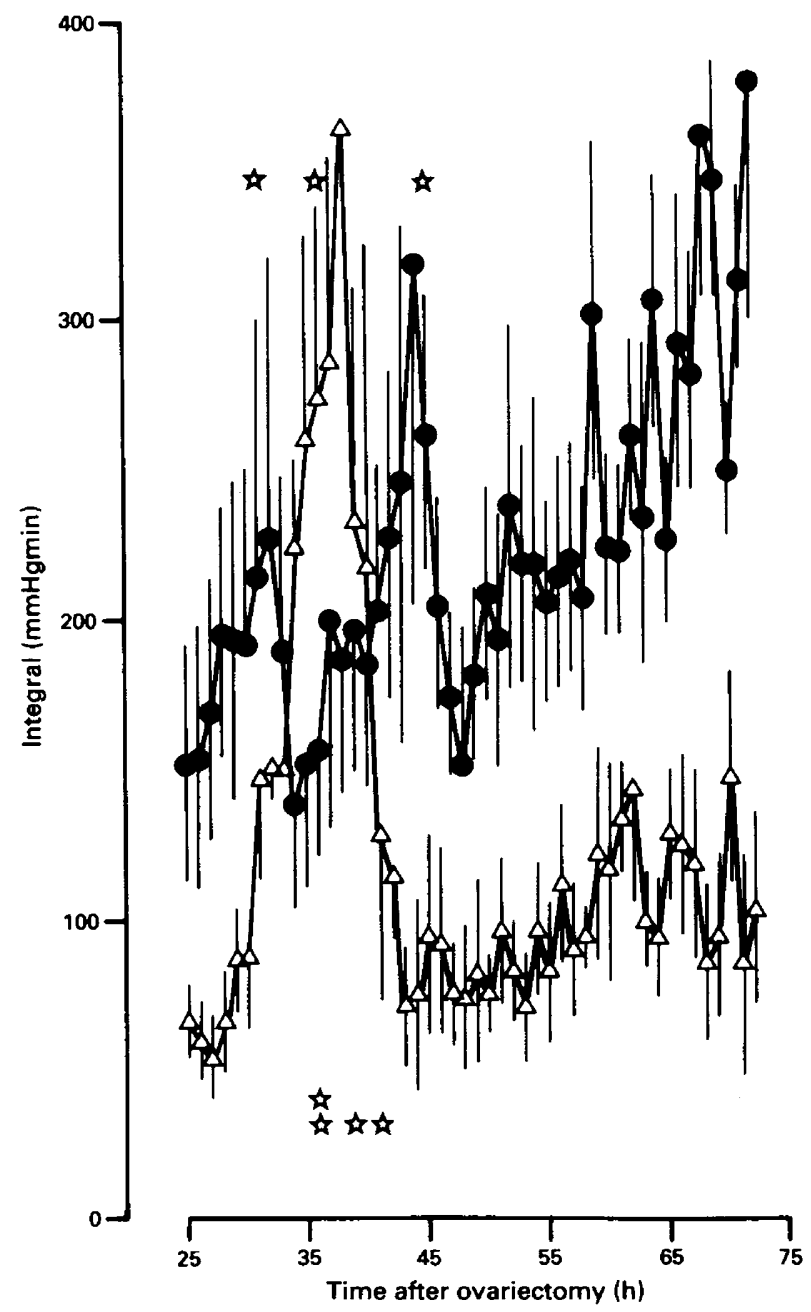

Fig. 1. Uterine contractions expressed as integral in 1 -h periods in pregnant rats, ovariectomized on Day 18 of gestation, treated with oestradiol benzoate $(1 \mu \mathrm{g} / \mathrm{kg} / 24 \mathrm{~h})$ and infused with saline $(0.4 \mathrm{ml} / \mathrm{h}, \mathrm{N}=6,0)$ or salbutamol $(2 \mu \mathrm{g} / \mathrm{kg} / \mathrm{min}, \mathrm{N}=5, \triangle)$. Values are means \pm s.e.m. is, times of first observed presence of fetuses. 
Table 1. Total uterine contractions expressed as integral (mmHgmin) between 25 and $72 \mathrm{~h}$ after ovariectomy and uterine, fetal and placental weights of rats at post mortem on Day 21 after infusion of saline, salbutamol, diltiazem, nifedipine vehicle or nifedipine from $5 \mathrm{~h}$ after ovariectomy on Day 18 and twice daily treatment with oestradiol benzoate $(0 \cdot 5 \mu \mathrm{g} / \mathrm{kg})$

\begin{tabular}{|c|c|c|c|c|c|c|}
\hline & \multirow[b]{2}{*}{ Saline } & \multirow{2}{*}{$\begin{array}{c}\text { Salbutamol } \\
(2 \mu \mathrm{g} / \mathrm{kg} / \\
\text { min) }\end{array}$} & \multirow{2}{*}{$\begin{array}{c}\text { Diltiazem } \\
(100 \mu \mathrm{g} / \mathrm{kg} / \\
\mathrm{min})\end{array}$} & \multirow[b]{2}{*}{$\begin{array}{l}\text { Nifedipine } \\
\text { vehicle }\end{array}$} & \multicolumn{2}{|c|}{ Nifedipine } \\
\hline & & & & & $\begin{array}{c}6.2 \mu \mathrm{g} / \mathrm{kg} / \\
\min \S\end{array}$ & $\underset{\min }{3 \cdot 1 \mu \mathrm{g} / \mathrm{kg} /}$ \\
\hline Uterine contractions & ${ }^{2} 10818 \pm$ & $\begin{array}{c}\mathrm{b}_{5977} \pm \\
437\end{array}$ & $\begin{array}{c}{ }^{b} 476 \dot{4} \pm \\
787\end{array}$ & ${ }^{a} 11034 \pm$ & $\begin{array}{c}2074 \pm \\
410\end{array}$ & $\begin{array}{c}\text { b,c } 4478 \pm \\
1269\end{array}$ \\
\hline Uterine wt (g) & $\begin{array}{c}4 \cdot 7 \pm \\
1 \cdot 7\end{array}$ & $\begin{array}{c}5 \cdot 7 \pm \\
1 \cdot 2\end{array}$ & $\begin{array}{c}41 \cdot 6 \pm \\
2 \cdot 5\end{array}$ & $\begin{array}{c}4 \cdot 4 \pm \\
1 \cdot 1\end{array}$ & $\begin{array}{c}53.9 \pm \\
6.9\end{array}$ & $\begin{array}{c}44 \cdot 2 \pm \\
5 \cdot 9\end{array}$ \\
\hline$\%$ Fetuses in utero & $\begin{array}{c}7 \cdot 1 \pm \\
2 \cdot 7\end{array}$ & $\begin{array}{c}9 \cdot 4 \pm \\
2.6\end{array}$ & $\begin{array}{c}89 \cdot 1 \pm \\
7 \cdot 3\end{array}$ & $\begin{array}{c}3 \cdot 5 \pm \\
2 \cdot 1\end{array}$ & $\begin{array}{c}91 \cdot 4 \pm \\
3 \cdot 1\end{array}$ & $\begin{array}{c}74 \cdot 6 \pm \\
9 \cdot 6\end{array}$ \\
\hline Fetal wt $(\mathrm{g})$ & $\begin{array}{c}* 0.85 \\
0.52\end{array}$ & $\begin{array}{c}\dagger^{*} 1.51 \\
0.38\end{array}$ & $\begin{array}{c}* 2.54 \pm \\
0.32\end{array}$ & $3.09 \ddagger$ & $\begin{array}{c}* 2.63 \pm \\
0.16\end{array}$ & $\begin{array}{c}* 2.47 \\
0.22\end{array}$ \\
\hline Placental wt (g) & $\begin{array}{c}* 0.30 \pm \\
0.03\end{array}$ & $\begin{array}{c}0.49 \pm \\
0.08\end{array}$ & $\begin{array}{c}{ }^{*} 0.42 \pm \\
0.02\end{array}$ & $\begin{array}{c}{ }^{*} 0.46 \pm \\
0.03\end{array}$ & $\begin{array}{c}0.52 \pm \\
0.02\end{array}$ & $\begin{array}{c}{ }^{*} 0.45 \pm \\
0.01\end{array}$ \\
\hline No. of dams & 6 & 5 & 5 & 5 & 4 & 6 \\
\hline
\end{tabular}

Values are means \pm s.e.m. Different letters within a row denote significant difference between groups $(P<0 \cdot 01)$.

*Significantly lower $(P<0 \cdot 01)$ than unoperated Day 21 controls.

†Includes one fetus trapped by balloon, weight $3.7 \mathrm{~g}$.

$\ddagger$ Two fetuses trapped by balloon, weights 4.45 and $1.73 \mathrm{~g}$.

$\S$ Survivors only.

of activity consisting of periods of continuous uterine contractions occurred between 30 and $32 \mathrm{~h}$ and 40 and $45 \mathrm{~h}$ after operation coinciding with expulsion of fetuses. At post mortem on Day 21 , only $7 \cdot 1 \pm 2 \cdot 7 \%$ of fetuses remained in utero (Table 1 ). The majority of these were undergoing resorption.

In 5 animals receiving an infusion of the nifedipine vehicle, the integral and pattern of uterine contractions were comparable with those seen in the saline-infused group (Figs 1 \& 3) and only $3 \cdot 5 \pm 2 \cdot 1 \%$ of fetuses were found in utero of Day 21 (Table 1 ).

\section{Salbutamol-infused animals}

The total integral of uterine contractions between 25 and $72 \mathrm{~h}$ after operation was significantly less in the salbutamol-infused compared with the saline-infused animals (Table 1). In addition the overall pattern of activity differed. There was an initial peak of activity between 30 and $40 \mathrm{~h}$ in the salbutamol group, comparable with that seen in the saline-infused animals and coinciding with expulsion of the fetuses (Fig. 1). After delivery of the fetuses uterine contractions decreased in the salbutamol-infused animals; regular bursts of uterine contractions were still seen but the amplitude of these contractions was lower and the time between bursts of contractions was increased in some animals compared with saline-infused animals. At post mortem $9 \cdot 4 \pm 2.6 \%$ of fetuses remained in utero (Table 1). Again the majority were undergoing resorption with the exception of one retained fetus which appeared to be trapped beyond the balloon. The weight of this fetus, $3.70 \mathrm{~g}$, was comparable with that of fetuses from unoperated animals on Day 21 of gestation $(4.00 \pm 0.31 \mathrm{~g})$.

\section{Diltiazem-infused animals}

An initial infusion of $200 \mu \mathrm{g} / \mathrm{kg} / \mathrm{min}$ was chosen as this dose rate abolished uterine contractions when infused into the post-partum ovariectomized rat. However, when the equivalent dose of nifedipine had to be reduced because of toxic effects, the dose rate of diltiazem was halved to 


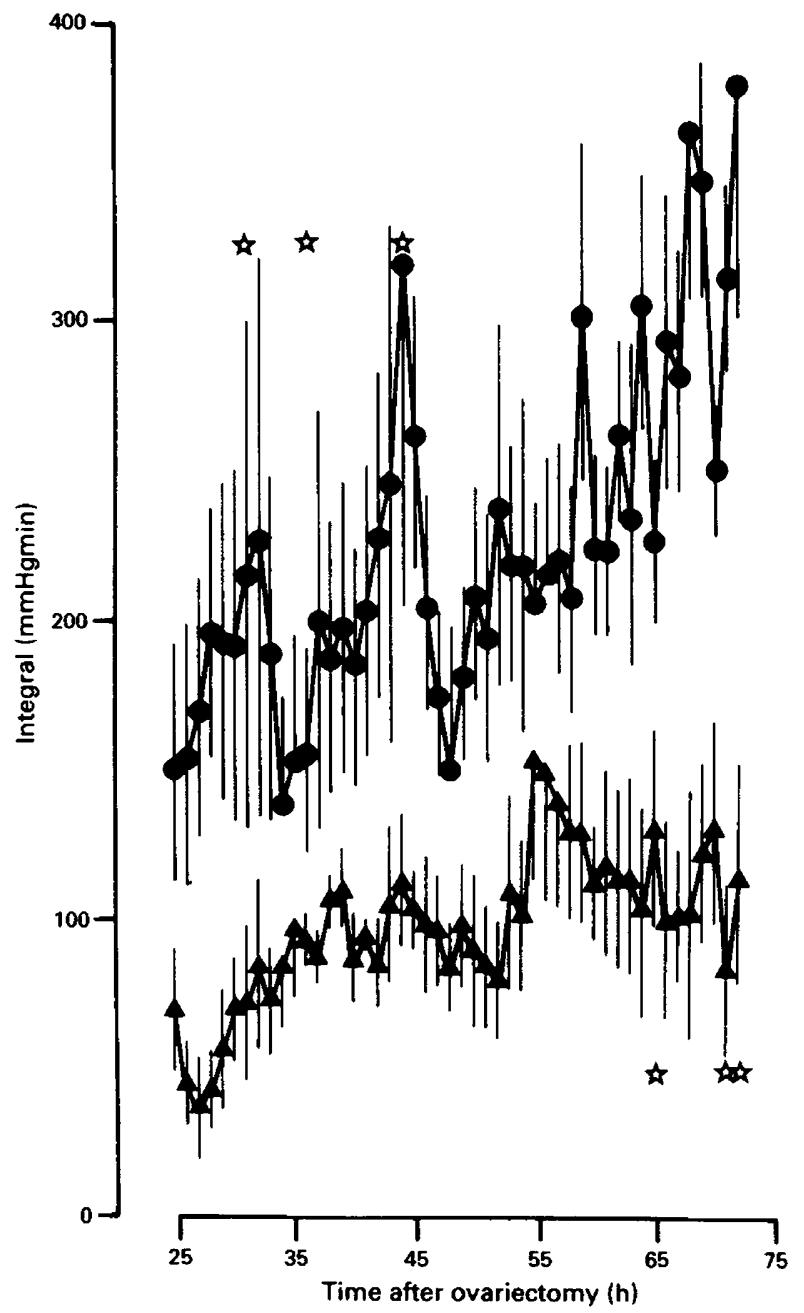

Fig. 2. Uterine contractions expressed as integral in 1-h periods in pregnant rats, ovariectomized on Day 18 of gestation, treated with oestradiol benzoate $(1 \mu \mathrm{g} / \mathrm{kg} / 24 \mathrm{~h})$ and infused with saline $(0.4 \mathrm{ml} / \mathrm{h}, \mathrm{N}=6,0)$ or diltiazem $(100 \mu \mathrm{g} / \mathrm{kg} / \mathrm{min}, \mathrm{N}=5, \Delta)$. Values are means \pm s.e.m. $\hat{i}$, times of first observed presence of fetuses.

$100 \mu \mathrm{g} / \mathrm{kg} / \mathrm{min}$. The total integral of uterine contractions recorded between 25 and $72 \mathrm{~h}$ after ovariectomy was significantly lower than that seen in the saline-infused animals (Table 1). Although the total integral of uterine contractions was not significantly lower than that in the salbutamol-infused animals, the pattern of activity was very different (Fig. 2). Low-amplitude, high-frequency continuous contractions were seen in the diltiazem group with a gradual increase in amplitude over the recording period. There was no peak of activity around $35 \mathrm{~h}$. At post mortem on Day 21 of gestation, $89 \cdot 1 \pm 7 \cdot 3 \%$ of fetuses were present in utero. Partial delivery had occurred in two animals with fetuses delivered at $65 \mathrm{~h}$ and $70-71 \mathrm{~h}$ respectively. In both cases the fetuses were alive at delivery but were subsequently eaten by their mothers. The fetuses remaining in utero were alive but the fetal and placental weights $(2.54 \pm 0.32 \mathrm{~g}, \mathrm{~N}=5$ and $0.42 \pm 0.02 \mathrm{~g}, \mathrm{~N}=5$ respectively) were significantly lower $(P<0.01)$ than the weights of fetuses $(4.00 \pm 0.31 \mathrm{~g}, \mathrm{~N}=6)$ and placentae $(0.55 \pm 0.02 \mathrm{~g}$, $\mathrm{N}=6$ ) from unoperated controls on Day 21 and comparable with those weights on Day 20 of gestation $(2 \cdot 14 \pm 0.06 \mathrm{~g}, \mathrm{~N}=5$ and $0.48 \pm 0.04 \mathrm{~g}, \mathrm{~N}=5$ respectively). 


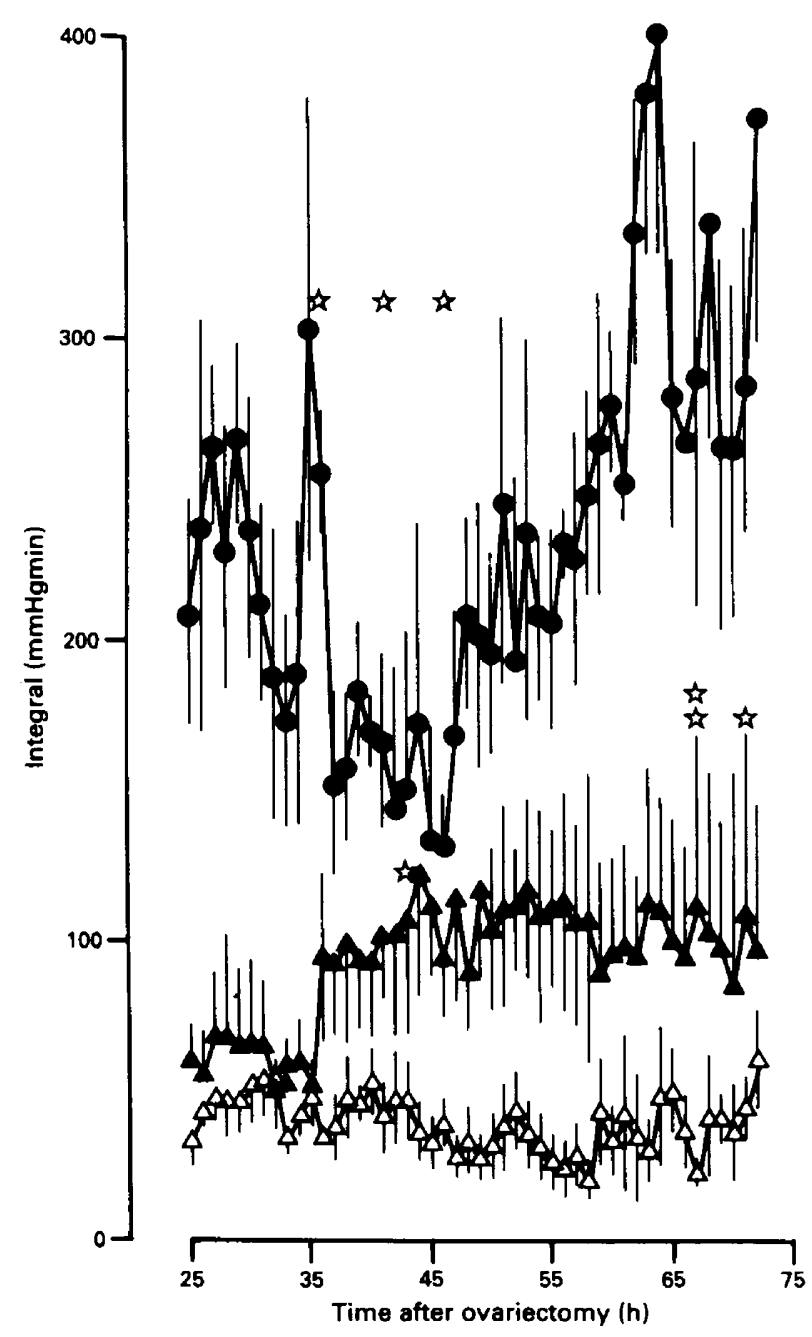

Fig. 3. Uterine contractions expressed as integral in 1 -h periods in pregnant rats, ovariectomized on Day 18 of gestation, treated with oestradiol benzoate $(1 \mu \mathrm{g} / \mathrm{kg} / 24 \mathrm{~h})$ and infused with nifedipine vehicle (polyethylene glycol 400:ethanol:saline, 15:15:50 by vol., $\mathrm{N}=5,0$ ) or nifedipine $(3 \cdot 1 \mu \mathrm{g} / \mathrm{kg} / \mathrm{min}, \mathrm{N}=6, \Delta ; 6 \cdot 2 \mu \mathrm{g} / \mathrm{kg} / \mathrm{min}, \mathrm{N}=7$ initially but 3 dams died between 58 and $63 \mathrm{~h}$, so after $64 \mathrm{~h} \mathrm{~N}=4, \triangle$ ). Values are means \pm s.e.m. $\vec{\xi}$, times of first observed presence of fetuses.

\section{Nifedipine-infused animals}

The initial infusion rate selected, $25 \mu \mathrm{g} / \mathrm{kg} / \mathrm{min}$, and in a second group of rats half this dose rate, proved lethal to approximately $50 \%$ of the dams $50-60 \mathrm{~h}$ after the start of infusion. In a third group a dose rate of $6 \cdot 2 \mu \mathrm{g} / \mathrm{kg} / \mathrm{min}$ was infused and 3 out of 7 animals died between 58 and $63 \mathrm{~h}$. Therefore, a further 6 animals were infused with $3 \cdot 1 \mu \mathrm{g} / \mathrm{kg} / \mathrm{min}$ and all animals survived to $72 \mathrm{~h}$ after ovariectomy.

The total integral of uterine contractions in the rats infused with $6 \cdot 2$ or $3 \cdot 1 \mu \mathrm{g} / \mathrm{kg} / \mathrm{min}$ between 25 and $72 \mathrm{~h}$ after ovariectomy was significantly lower than in the saline-infused animals. In addition, the total integral of uterine contractions was significantly lower in the animals receiving $6.2 \mu \mathrm{g} / \mathrm{kg} / \mathrm{min}$ compared with those infused with $3 \cdot 1 \mu \mathrm{g} / \mathrm{kg} / \mathrm{min}$ (Fig. 3; Table 1). When contractions were present 
they resembled those seen with diltiazem, i.e. low-amplitude, high-frequency and continuous. There was little change in amplitude during the infusion. In the 4 animals which survived to Day 21 in the group receiving $6 \cdot 2 \mu \mathrm{g} / \mathrm{kg} / \mathrm{min}, 91.4 \pm 3 \cdot 1 \%$ of fetuses were alive in utero. Fetal weight $(2.63 \pm 0.15 \mathrm{~g}, \mathrm{~N}=4)$, although significantly lower $(P<0.01)$ than fetal weights in unoperated rats on Day 21 of gestation, was significantly higher $(P<0.05)$ than on Day 20 of gestation. Placental weights $(0.52 \pm 0.02 \mathrm{~g}, \mathrm{~N}=4)$ were similar to those of unoperated fetuses on Day 21. In the group receiving $3 \cdot 1 \mu \mathrm{g} / \mathrm{kg} / \mathrm{min}, 74.6 \pm 9 \cdot 6 \%$ of fetuses were found in utero on Day 21 and again the fetal and placental weights $(2.47 \pm 0.22 \mathrm{~g}, \mathrm{~N}=6$, and $0.45 \pm 0.02 \mathrm{~g}, \mathrm{~N}=6$, respectively) were significantly lower $(P<0.01)$ than in control fetuses of the same gestational age, being comparable with those of fetuses on Day 20 of gestation. Partial delivery had occurred in 5 out of the 6 animals in the low-dose group with $50 \%$ loss of fetuses in 2 animals. Timing of delivery was more difficult in nifedipine-infused animals because the experiments were carried out under sodium light and any blood loss, which acted as an early indicator of fetal delivery, could not be detected. However, in one animal fetuses were seen to be born at $43 \mathrm{~h}$ and at $67 \mathrm{~h}$.

Animals treated with diltiazem or nifedipine were relatively inactive throughout the period of infusion compared with saline-infused or salbutamol-infused animals, but appeared to be eating and drinking normally.

\section{Plasma progesterone concentrations}

Mean plasma progesterone concentrations in the experimental animals before ovariectomy did not differ significantly from concentrations in unoperated controls on Day 18 of gestation. Progesterone concentrations decreased gradually in unoperated controls from Day $18(94.3 \pm 16.5 \mathrm{ng} / \mathrm{ml}$, $\mathrm{N}=5)$ to Day $21(44 \cdot 2 \pm 12 \cdot 6 \mathrm{ng} / \mathrm{ml}, \mathrm{N}=6)$ and in all of the ovariectomized, drug-infused groups concentrations were $<4.0 \mathrm{ng} / \mathrm{ml}$ by Day 21 (Table 2 ).

Table 2. Plasma progesterone concentrations of rats before ovariectomy on Day 18 of gestation and on Day 21 of gestation, $72 \mathrm{~h}$ after ovariectomy

\begin{tabular}{|c|c|c|c|}
\hline \multirow[b]{2}{*}{ Drug infused } & \multirow[b]{2}{*}{ Dose rate } & \multicolumn{2}{|c|}{ Progesterone conc. $(\mathrm{ng} / \mathrm{ml})$} \\
\hline & & Day 18 & Day 21 \\
\hline Saline & & $128 \cdot 2 \pm 12 \cdot 0$ & $1 \cdot 3 \pm 0.4$ \\
\hline Salbutamol & $2 \mu \mathrm{g} / \mathrm{kg} / \mathrm{min}$ & $93 \cdot 1 \pm 12 \cdot 2$ & $1.4 \pm 0.4$ \\
\hline Diltiazem & $100 \mu \mathrm{g} / \mathrm{kg} / \mathrm{min}$ & $83.9 \pm 13.4$ & $2.9 \pm 0.9$ \\
\hline Nifedipine vehicle & & $79.4 \pm 2.8$ & $1 \cdot 1 \pm 0.3$ \\
\hline Nifedipine & $6.2 \mu \mathrm{g} / \mathrm{kg} / \min$ & $80 \cdot 1 \pm 1 \cdot 0$ & $3 \cdot 3 \pm 0.6$ \\
\hline & $3.1 \mu \mathrm{g} / \mathrm{kg} / \mathrm{min}$ & $87.3 \pm 4.4$ & $2.9 \pm 0.7$ \\
\hline
\end{tabular}

Values are means \pm s.e.m., for $4-6$ rats.

\section{Discussion}

The present study has demonstrated that salbutamol did not prevent preterm delivery in the ovariectomized, oestrogen-treated late pregnant rat. By contrast, diltiazem and nifedipine produced sustained suppression of uterine contractions, prolonged gestation and maintained fetal survival in utero.

It is well recognized that ovariectomy of the pregnant rat results in fetal resorption and preterm expulsion of the fetuses (Csapo, Csapo, Fay, Henzl \& Salau, 1973). Thus the ovariectomized pregnant rat appears to provide features which would be of use in assessing the effectiveness of drugs of 
potential clinical use in preterm labour. However, in the rat the preterm expulsion of the fetuses occurs less predictably the later in gestation ovariectomy is carried out (Csapo et al., 1973). Similarly, we observed (unpublished observations) that of 14 animals ovariectomized on Day 18 of gestation $90 \%$ or more of fetuses were retained in utero in over half the animals. For this reason we, like Csapo et al. (1982), supplemented ovariectomy with subcutaneous injection of oestradiol benzoate and preterm delivery occurred in all animals with this treatment between 30 and $45 \mathrm{~h}$ after ovariectomy. Ovariectomy in the pregnant (Hollingsworth \& Gallimore, 1981) and post-partum (Downing \& Porter, 1980; Abel \& Hollingsworth, 1985a) rat results in the appearance of uterine contractions of regular amplitude and frequency. Oestradiol-17 $\beta$ has been shown to suppress these contractions in the post-partum rat, acting to decrease the frequency of contractions without changing amplitude (Downing, Lye, Bradshaw \& Porter, 1978; Downing \& Porter, 1980). It is likely that the sporadic nature of the contractions in the saline-infused and salbutamol-infused animals in this study was a consequence of the injected oestradiol benzoate. Despite the overall decrease in uterine contractions produced by oestrogen treatment of ovariectomized pregnant rats, the contractions eventually evolved to produce delivery.

Infusion of salbutamol at a dose rate which in the post-partum rat initially produced complete suppression of uterine contractions (Abel \& Hollingsworth, 1985b, 1986) did not in the present study prevent the development of uterine contractions during the period $24-37 \mathrm{~h}$ after ovariectomy in the pregnant rat. In the salbutamol-infused animals abortion occurred in all animals at a time not different from that in saline-infused animals. It is clear that the factors responsible for expulsion of fetuses were still able to cause contraction of the uterus in the presence of salbutamol. In the post-partum rat, despite continuous infusion of salbutamol, there was the reappearance of uterine contractions after $2 \mathrm{~h}$ and eventual return of contractions to a magnitude seen in the control period. This was associated with a more than 100 -fold decrease in sensitivity to salbutamol and it was concluded that marked tolerance had occurred to the inhibitory action of salbutamol on the uterus (Abel \& Hollingsworth, 1985b, 1986). These observations of tolerance are in line with similar reports for the non-pregnant rat and pregnant human uterus and other $\beta$-adrenoceptor agonists, isoprenaline and terbutaline (Johansson \& Andersson, 1981; Rydén et al., 1982; Berg et al., 1985). It is therefore likely that tolerance also occurred in the present experiments with ovariectomized, oestrogen-treated late pregnant rats. This would explain the failure of salbutamol to prolong gestation. Tolerance to $\beta$-adrenoceptor agonists is initially detected as decreased production of cyclic $3^{\prime}, 5^{\prime}$-adenosine monophosphate on repeated stimulation with an agonist (Johansson \& Andersson, 1981). The phenomenon has been attributed to functional alteration of the $\beta$-adrenoceptor due to uncoupling of the receptors from their regulatory subunit accompanied by a decrease in receptor number with continued stimulation due to internalization of the receptors in membrane-bound vesicles (Harden, 1983; Stiles, Caron \& Lefkowitz, 1984). Some of these biochemical changes have been observed in the myometrium of the pregnant woman (Berg et al., 1985).

In this study uterine contractions in the salbutamol-infused animals decreased after abortion and the integral values remained lower than in the saline-infused animals where there was an increase during the remaining infusion period. This observation with salbutamol is clearly different from the findings in the post-partum rat (Abel \& Hollingsworth, 1985b, 1986) and may in part be explained by the differences in hormonal status. In the present study the oestrogen treatment may have augmented the action of salbutamol on the uterus and partly reversed the tolerance. It has been shown that oestradiol increased the number of binding sites for $\beta$-adrenoceptor agonists in rat myometrium (Krall, Mori \& Korenman, 1977).

Both diltiazem and nifedipine have been shown for the first time to produce a marked and sustained inhibition of uterine contractions in the pregnant rat and to prolong fetal survival in utero. For diltiazem the effects on the uterus here are in accord with similar observations in the post-partum ovariectomized rat at similar dose rates (Abel \& Hollingsworth, 1985b, 1986). In the study of Abel \& Hollingsworth (1986), a partial return of uterine contractions was observed in a few animals despite continued diltiazem infusion. In the pregnant rats there was some increase in uterine con- 
tractions during the diltiazem infusion. In addition, partial delivery occurred in 2 out of 5 animals. There may, therefore, be some tolerance to the inhibitory action of diltiazem on the uterus of the pregnant rat. However, preterm labour was significantly delayed in all animals by this dose rate of diltiazem.

With nifedipine an increase in dose rate from $3 \cdot 1$ to $6 \cdot 2 \mu \mathrm{g} / \mathrm{kg} / \mathrm{min}$ increased inhibition of uterine contractions and improved fetal retention in utero. However, maternal deaths occurred in $43 \%$ of the animals after 53-58 $\mathrm{h}$ infusion at the higher dose rate. The fetal weights in the animals which died were significantly lower than those in the survivors and the fetuses frequently had enlarged livers and white extremities suggesting inadequate placental perfusion.

Diltiazem and nifedipine have in common negative inotropic properties and an ability to relax vascular smooth muscle (Nayler \& Horowitz, 1983; Granger et al., 1985). They are therefore likely to have had marked effects on blood pressure and heart rate at the dose rates used in this study. The lower fetal weights found on Day 21 of gestation in both the diltiazem-infused and nifedipine-infused animals compared with unoperated controls may be due to growth retardation resulting from decreased uterine blood flow secondary to these cardiovascular changes. There is evidence for three sub-classes of calcium antagonists of which diltiazem and nifedipine are representatives of two different sub-groups (Spedding, 1982; Granger et al., 1985). The greater vascular selectivity of nifedipine compared with diltiazem may underlie the maternal toxicity seen here with nifedipine but not with diltiazem.

Both diltiazem and nifedipine were potent inhibitors of contractions of the rat uterus in vitro (Granger et al., 1985, 1986) and had the same action in vivo with a rapid onset after i.v. bolus injection (Abel \& Hollingsworth, 1985a). The simplest explanation for their inhibitory effects on uterine contractions is a direct action on the myometrium and this in turn can explain their ability to prolong gestation. Plasma progesterone concentrations fell to $<4 \mathrm{ng} / \mathrm{ml}$ in all ovariectomized animals by Day 21 , in test and control animals, indicating that none of the drugs enhanced extraovarian production of progesterone which could in turn have explained the prolongation of preterm gestation.

In summary, while all three drugs investigated can inhibit uterine contractions acutely in vivo (Abel \& Hollingsworth, 1985a), this action can not necessarily be extrapolated to predict an ability to prevent preterm delivery. The inability of salbutamol to induce long-term suppression of uterine contractions and failure to prevent preterm delivery can be explained by tolerance to its action. With nifedipine there was the development of maternal toxicity after prolonged infusion which was not evident after either acute administration or $20 \mathrm{~h}$ of infusion (Abel \& Hollingsworth, 1985a, b, 1986).

We thank the North West Regional Health Authority and the MRC for financial support; Dr M. Dukes for the progesterone measurements; and the companies which provided the drugs listed under 'Materials and Methods'.

\section{References}

Abel, M.H. \& Hollingsworth, M. (1985a) The potencies and selectivities of four calcium antagonists as inhibitors of uterine contractions in the rat in vivo. Br.J. Pharmac. 85, 263-269.

Abel, M.H. \& Hollingsworth, M. (1985b) Tolerance to salbutamol on the rat uterus in vivo compared with nifedipine and diltiazem. Br. J. Pharmac. 85, Proc. Suppl., 331P.

Abel, M.H. \& Hollingsworth, M. (1986) The effects of long term infusion of salbutamol, diltiazem and nifedipine on uterine contractions in the ovariectomised postpartum rat. Br.J. Pharmac. (in press).

Berg, G., Andersson, R.G.G. \& Rydén, G. (1985) ß-
Adrenergic receptors in human myometrium during pregnancy: changes in the numbers of receptors after $\beta$-mimetic treatment. Am. J. Obstet. Gynec. 151, 392-396.

Bolton, T.B. (1979) Mechanisms of action of transmitters and other substances on smooth muscle. Physiol. Rev. 59, 606-692.

Csapo, A.I., Csapo, E.F., Fay, E., Henzl, M.R. \& Salau, G. (1973) The role of estradiol-17 $\beta$ in the activation of the uterus during premature labor and the effect of naproxen-an inhibitor of prostaglandin synthesis. Prostaglandins 3, 839-846.

Csapo, A.I., Puri, C.P., Tarro, S. \& Henzl, M.R. (1982) 
Deactivation of the uterus during normal and premature labor by the calcium antagonist nicardipine. $\mathrm{Am}$. J. Obstet. Gynec. 142, 483-491.

Downing, S.J. \& Porter, D.G. (1980) Oestrogen-induced myometrial quiescence in the post-partum rat is not mediated by adrenaline or by $\alpha$ - or $\beta$-adrenoceptor activation. J. Endocr. 85, 405-413.

Downing, S.J., Lye, S.J., Bradshaw, J.M.C. \& Porter, D.G. (1978) Rat myometrial activity in vivo: effects of oestradiol-17\% and progesterone in relation to the concentrations of cytoplasmic progesterone receptors. J. Endocr. 78, 103-117.

Edman, K.A.P. \& Schild, H.O.(1962) The need for calcium in the contractile responses induced by acetylcholine and potassium in the rat uterus. J. Physiol., Lond. 161, 424-441.

Forman, A., Andersson, K-E. \& Ulmsten, U. (1981) Inhibition of myometrial activity by calcium antagonists. Sem. Perinat. 5, 288-294.

Granger, S.E., Hollingsworth, M. \& Weston, A.H. (1985) A comparison of several calcium antagonists on uterine, vascular and cardiac muscles from the rat. Br. J. Pharmac. 85, 255-262.

Granger, S.E., Hollingsworth, M. \& Weston, A.H. (1986) Effect of calcium entry blockers on tension development and calcium influx in rat uterus. Br. J. Pharmac. 87, 147-156.

Hahn, D.W., McGuire, J.L., Vanderhoof, M., Ericson, E. \& Pasquale, S.A. (1984) Evaluation of drugs for arrest of premature labor in a new animal model. $\mathrm{Am}$. J. Obstet. Gynec. 148, 775-778.

Harden, T.K. (1983) Agonist-induced desensitization of the $\beta$-adrenergic receptor-linked adenylate cyclase. Pharmac. Rev. 35, 5-32.

Hollingsworth, M. \& Gallimore, S. (1981) Evidence that cervical softening in the pregnant rat is independent of increasing uterine contractility. J. Reprod. Fert. 63, 449-454.
Johansson, S.R.M. \& Andersson, R.G.G. (1981) Mechanisms of $\beta$-adrenergic desensitization in rat myometrium. Acta pharmac. toxic. 49, 241-247.

Krall, J.F., Mori, H. \& Korenman, S.G. (1977) Molecular basis of drug action on uterine smooth muscle. In Pre-Term Labour, pp. 79-100. Eds A. Anderson, R. Beard, J. M. Brudenhall \& P. M. Dunn. Royal College of Obstetricians and Gynaecologists, London.

Lippert, T.H. (1983) Tocolytic therapy for preterm labour. In Clinical Pharmacology in Obstetrics, $\mathrm{Ch}$. 15, pp. 182-218. Ed. P. J. Lewis. John Wright \& Sons, Bristol.

Nayler, W.G. \& Horowitz, J.D. (1983) Calcium antagonists: a new class of drugs. Pharmac. Ther. 20, 203-262.

Rydén, G., Andersson, R.G.G. \& Berg, G. (1982) Is the relaxing effect of $\beta$-adrenergic agonists on the human myometrium only transitory? Acta obstet. gynaec. scand., Suppl. 108, 47-51.

Sakamoto, H. \& Hucszar, G. (1984) Nitrendipine prolongs rat parturition: no changes occur in progesterone withdrawal. Endocrinology 84, 959-961.

Spedding, M. (1982) Assessment of " $\mathrm{Ca}^{2+}$-antagonist" effects of drugs in $\mathrm{K}^{+}$-depolarised smooth muscle. Naunyn-Schmiedebergs Arch. exp. Path. Pharmak. 318, 234-240.

Stiles, G.L., Caron, M.G. \& Lefkowitz, R.J. (1984) B-Adrenergic receptors: biochemical mechanisms of physiological regulation. Physiol. Rev. 64, 661-743.

Williams, L.M., Hollingsworth, M., Dukes, M. \& Morris, I.D. (1983) Fluprostenol-induced softening of the cervix of the pregnant rat. J. Endocr. 97, 283-290.

Received 30 October 1985 